\title{
Seepage and Dynamic Characteristics of Carbonaceous Mudstone Coarse-Grained Soil Embankment with Different Gradations
}

\author{
Zhong-ming He, ${ }^{1,2}$ Xiao-qu Liu $\mathbb{D}^{2}{ }^{2}$ Ke Huang, ${ }^{2}$ and Jian-ping Xiong ${ }^{1}$ \\ ${ }^{1}$ Guangxi Transportation Science \& Technology Group, Nanning 530000, China \\ ${ }^{2}$ School of Traffic \& Transportation Engineering, Changsha University of Science \& Technology, Changsha 410114, China \\ Correspondence should be addressed to Xiao-qu Liu; 19101030063@stu.csust.edu.cn
}

Received 28 April 2021; Accepted 22 July 2021; Published 31 July 2021

Academic Editor: Rihong Cao

Copyright (C) 2021 Zhong-ming He et al. This is an open access article distributed under the Creative Commons Attribution License, which permits unrestricted use, distribution, and reproduction in any medium, provided the original work is properly cited.

\begin{abstract}
This study investigates the seepage and deformation characteristics of carbonaceous mudstone coarse-grained soil embankment with different gradations under the action of dynamic load and rainfall. An indoor geotechnical test is conducted, and the mechanical parameters of carbonaceous mudstone coarse-grained soil with different gradations are analyzed. A numerical calculation model of seepage and dynamic characteristics of carbonaceous mudstone coarse-grained soil embankment is established on the basis of the test data. The different effects of rainfall infiltration and vehicle load are evaluated. The seepage, settlement, and slope stability evolution characteristics of graded carbonaceous mudstone coarse-grained soil embankment slope are studied. Results show that under the condition of the same rainfall time, the greater the nonuniformity coefficient, the faster the decrease in pore water pressure of the coarse-grained soil embankment at the same monitoring point. The seepage velocity vector in the embankment is concentrated below the soil shoulder. The smaller the saturated permeability coefficient and saturated water content, the larger the seepage velocity vector. The greater the nonuniformity coefficient, the larger the coarse-grained soil embankment under vehicle load. The smaller the embankment settlement, the lower the safety factor of embankment. The safety factor decreases slowly at first and then decreases rapidly in the whole study period under the effect of dynamic wetting. The research results provide a theoretical reference for the practical engineering application of carbonaceous mudstone coarse-grained soil embankment in rainy areas.
\end{abstract}

\section{Introduction}

Carbonaceous mudstone is widely distributed in southwest China $[1,2]$. It was often discarded as bad filling material in highway construction in the past due to its strong water resistance, easy weathering, low strength, and large deformation. However, with the rapid development of highway construction in China, suitable filling materials are extremely scarce in many areas. Considering the economy and environmental protection, the use of carbonaceous mudstone for embankment filling is imperative. However, the rheological phenomenon of coarse-grained soil filler often occurs during the operation period under long-term vehicle dynamic load and rainwater infiltration. This condition leads to the gradual weakening of the service performance (water stability, strength, and stability) of high embankment with coarse-grained soil and then causes the local or overall instability of high embankment $[3,4]$. Considering this problem, scholars at home and abroad have conducted numerous research and considered that the influence of seepage and dynamic load on embankment is mainly reflected in the following aspects: (1) the change in matric suction of unsaturated soil is mainly caused by gradation [5]; (2) the seepage flow along the embankment slope direction during rainfall infiltration increases the overall sliding force of the slope [6,7]; (3) the rainfall infiltration reduces the matric suction of unsaturated soil, and mass suction leads to the decrease in soil shear strength [8].

In the aspect of the influence of gradation on the hydraulic characteristics of coarse-grained soil, Wang et al. [9] investigated the influence of gradation on the hydraulic characteristics of coarse-grained soil. On the basis of Van Genuchten 
(VG) water retention model, two pedotransfer functions are proposed by using semiphysical and semistatistical methods to estimate the water retention curve of sand. Feng et al. [10] studied the influence of porosity and fractal dimension of particles on the seepage characteristics of sandstone. Chiu et al. [11] presented a method to estimate the soil-water characteristic curve by using particle size distribution. Meng et al. [12] explored the deformation characteristics of coarsegrained soil with different gradations.

The particle size distribution of soil sample affects its hydraulic and mechanical parameters in different degrees. Therefore, the hydraulic and physical properties of carbonaceous mudstone coarse-grained soil embankment filling with different gradations are compared to investigate the deformation characteristics of carbonaceous mudstone filling with different gradations. This process can verify the feasibility of carbonaceous mudstone coarse-grained soil filling road and determine the feasibility of the project. The best graded carbonaceous mudstone coarse-grained soil embankment is determined in the project. However, the above studies only consider the influence of soil particle gradation and disregard the influence of soil load in the analysis of the hydraulic characteristics of soil.

In the aspect of saturated-unsaturated seepage of embankment slope, Wang et al. [8], Liu et al. [13], Kim et al. [14], and Kim et al. [15] studied the influence of water volume content and pore water pressure of unsaturated soil on slope stability under rainfall conditions. Wu et al. [16] conducted numerical analysis on unsaturated seepage of loess slope caused by rainfall infiltration and quantitatively evaluated the relationship between rainfall infiltration and slope stability by monitoring the water content, pore water pressure, and slope deformation of loess slope. Liu et al. [17], Volz et al. [18], and Kim et al. [19] conducted numerical simulation on the rainfall damage of unsaturated soil embankment slope and analyzed the influence of rainfall intensity, rainfall duration, and soil long-term intensity on the instability characteristics of unsaturated soil embankment slope under rainfall. Cho [20] and Nguyen and Likitlersuang [21] used numerical models to analyze the slope stability under heavy rainfall and predict the probability of slope instability. The above research results reveal the seepage characteristics of rainfall infiltration in the embankment and show that the numerical software can better simulate the gradual process of real embankment slope instability. In practical engineering, many factors affect the embankment deformation, and indoor model test is difficult to restore the real environment and vehicle load of the embankment. Therefore, the help of numerical analysis software to simulate the real situation of embankment deformation characteristics can maximize the simulation of the actual project, so as to lay a good theoretical foundation for practical engineering application. Relevant scholars have conducted many studies on the mechanical properties of carbonaceous mudstone. However, they only consider the influence of rainfall or static load. Few studies have been performed on the mechanical properties of carbonaceous mudstone coarse-grained soil embankment under the combined action of rainfall infiltration and dynamic load.
Research on the migration characteristics of seepage water in embankment under the combined action of vehicle load and rainfall infiltration is lacking at home and abroad. The aim of this study is thus to study the influence of rainfall infiltration and vehicle load on the seepage field and dynamic characteristics of carbonaceous mudstone coarsegrained soil slope with different gradations using the GeoStudio and FLAC 3D software. The influence of displacement field and stability evolution can provide theoretical guidance for engineering practice.

1.1. Analysis of Particle Size Distribution. According to engineering experience, disintegrated carbonaceous mudstone is generally used as embankment filler instead of bulk carbonaceous mudstone [22]. In this study, carbonaceous mudstone was placed outdoors for disintegration and was sprayed with appropriate amount of water every day until it was naturally dried. After 30 days, the carbonaceous mudstone coarse-grained soil was mixed with a shovel to mix it evenly [23]. The coarse granular soil of carbonaceous mudstone was screened. The gradation used in this study is based on the design data of the project, as shown in Table 1, and the gradation curve is shown in Figure 1. In this study, soil samples with three different gradations are called gradation 1, gradation 2, and gradation 3, respectively.

Existing research shows that when the fractal dimension is greater than 2.3, carbonaceous mudstone coarse-grained soil can be used as embankment [24] filler in accordance with the calculation formula of passing percentage and fractal dimension of carbonaceous mudstone coarse-grained soil [25]. The fractal dimension of carbonaceous mudstone coarse-grained soil used in this study after disintegration is shown in Table 2. The fractal dimension of each soil sample is greater than 2.3, which meets the requirements of road use.

1.2. Physical and Mechanical Parameters. The test data through the indoor geotechnical test of the soil sample prepared on the basis of the proposed gradation in the project are shown in Table 3. These data provide accurate physical and mechanical parameters for the subsequent numerical simulation.

\section{Analysis of the Seepage Characteristics of Embankment}

2.1. Seepage Numerical Model. This study establishes a seepage calculation model based on a highway carbonaceous mudstone coarse-grained soil embankment project in Guangxi to explore the seepage change law of carbonaceous mudstone coarse-grained soil embankment under different rainfall conditions. The embankment height is $8 \mathrm{~m}$, and the slope is $1: 1.5$. The specific geometric size is shown in Figure 2. GeoStudio numerical analysis software is used to establish the seepage numerical model, as shown in Figure 3. The mesh is divided in accordance with the four-node method [26], with a total of 2698 nodes and 2588 elements. Eleven monitoring points are set in the embankment slope model to analyze the variation of volume moisture content 
TABLE 1: Grading statistics of carbonaceous mudstone coarsegrained soil.

\begin{tabular}{lcccccc}
\hline Soil sample & $d_{10}$ & $d_{30}$ & $d_{60}$ & $C_{u}$ & $C_{c}$ & Fractal dimension \\
\hline Gradation 1 & 1.14 & 8.43 & 26.55 & 23.29 & 2.35 & 2.46 \\
Gradation 2 & 0.40 & 2.90 & 9.80 & 24.50 & 2.15 & 2.55 \\
Gradation 3 & 0.60 & 3.30 & 10.40 & 17.33 & 1.75 & 2.50
\end{tabular}

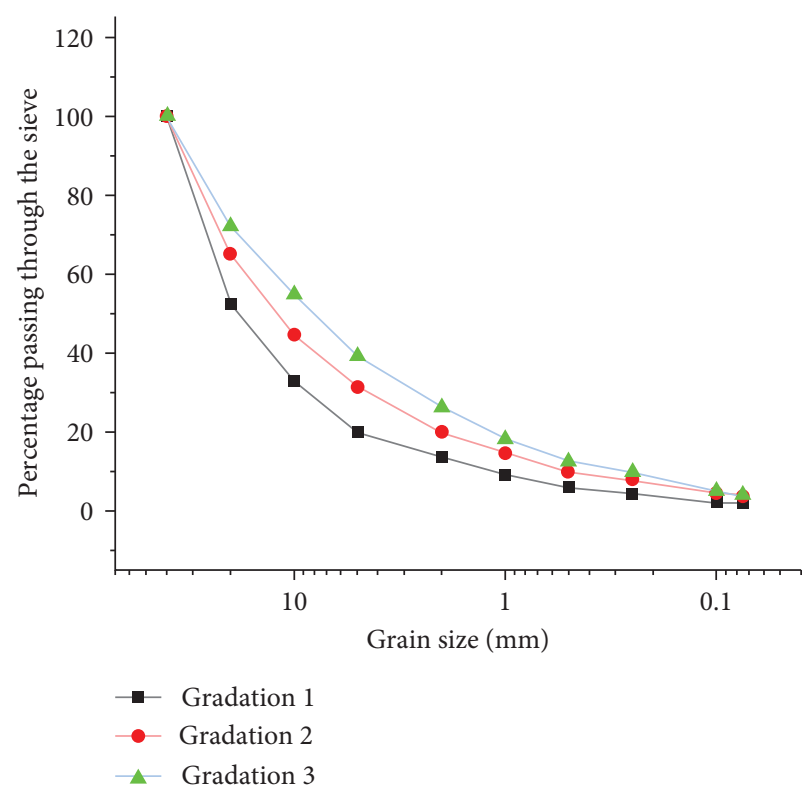

FIgURE 1: Particle size distribution curve.

in the process of rainwater seepage. The monitoring points 1-5 are buried at the depth of $0.5 \mathrm{~m}$ below the slope, and the spacing of each monitoring point is $3.2 \mathrm{~m}$. The monitoring points $6,8,9$, and 3 are in the same horizontal position, and the spacing of each monitoring point is $0.7 \mathrm{~m}$. The monitoring points 7,10 , and 11 are below monitoring point 3 , and their spacing is $0.7 \mathrm{~m}$, as shown in Figure 3.

In this model, the soil shoulder, embankment slope surface, and subgrade surface on the right side of the slope toe are taken as rainfall infiltration boundary, and the pavement is taken as impermeable boundary. The left groundwater level is set at the depth of $10 \mathrm{~m}$ below the carbonaceous mudstone coarse-grained soil embankment. The right groundwater level is set at the depth of $11 \mathrm{~m}$ below the carbonaceous mudstone coarse-grained soil embankment.

The influence of heavy rainfall on the slope seepage characteristics is evaluated on the basis of the local rainfall data. The rainfall intensity is determined to be $1.16 \times 10^{-6} \mathrm{~m} /$ $\mathrm{s}$, and the rainfall duration is $72 \mathrm{~h}$. The seepage parameters of soil with different gradations are shown in Table 2. The VG model is used to fit the soil-water characteristic curve of coarse-grained carbonaceous mudstone soil with different gradations, as shown in Figure 4.

2.2. Variation Law of the Negative Pore Water Pressure and Volume Moisture Content of Embankment. In the process of water level rise and fall, the pore water pressure in the embankment changes with the moisture migration. This study only lists the distribution of pore water pressure in the embankment of carbonaceous mudstone coarse-grained soil with different gradations at 24 and $72 \mathrm{~h}$, as shown in Figure 5 .

As shown in Figure 5, the variation trend of the pore water pressure of coarse-grained carbonaceous mudstone soil with different gradations is similar during rainfall infiltration. The continuous rainfall causes the groundwater level to rise, and the carbonaceous mudstone coarse-grained soil embankment forms a transient saturation zone at the bottom of the slope. Soil sample 2 has the largest rainfall infiltration depth compared with soil samples 1 and 3 .

Figures 6 and 7 show the variation curves of negative pore water pressure and volumetric water content with time at different depths of monitoring points under the effect of rainfall infiltration.

As shown in Figure 6, the negative pore water pressure of embankment slope gradually decreases with the increase in rainfall duration after the beginning of rainfall. The negative pore water pressure on the slope surface decreases fast, and the negative pore water pressure inside the slope decreases slowly. Within $35 \mathrm{~h}$ of rainfall, the negative pore water pressure of three grading soil samples at monitoring points 1-5 decreases to 0 . The order of decreasing rate is monitoring point $1>$ monitoring point $2>$ monitoring point $3>$ monitoring point $4>$ monitoring point 5 . The change law can be summarized in three stages: rapid decrease in 0-20 h, slow decrease in $20-35 \mathrm{~h}$, and basically stable in $35-72 \mathrm{~h}$. After $10 \mathrm{~h}$ of rainfall, soil sample 2 has a more obvious downward trend than soil samples 1 and 3 .

The hydraulic characteristics of soil sample 2 are better than that of soil samples 1 and 3 through comparative analysis. For soil sample 2, monitoring points 6 and 7 in the slope are reduced to $0 \mathrm{kPa}$ within $55 \mathrm{~h}$, and the reduction rate is monitoring point $6>$ monitoring point 7 . For monitoring points $3,6,8$, and 9 , the matric suction decreases from the slope surface to the slope interior. For monitoring point 11 of soil sample 2, the negative pore water pressure of soil sample 2 decreases rapidly from $120 \mathrm{kPa}$ to $40 \mathrm{kPa}$ within $35-72 \mathrm{~h}$ of rainfall, which decreases by $66 \%$.

As shown in Figure 7, the water content of the embankment slopes of three carbonaceous mudstone coarsegrained soil samples increases under the effect of rainfall. The water content of the points close to the slope surface increases rapidly. The transient saturation area gradually expands to the inside of the slope after forming at the surface of the embankment slope. The saturated water content of the soil at monitoring point 5 first reaches the top of the slope, and that of the soil at monitoring point 1 at the foot of the slope increases rapidly. The growth rate of negative pore water pressure is the slowest. For soil sample 2, the volumetric moisture content in monitoring points 1-5 located on the slope reaches saturation within $55 \mathrm{~h}$ of rainfall, and the order of increasing rate is monitoring point $1>$ monitoring point $2>$ monitoring point $3>$ monitoring point $4>$ monitoring point 5 . The monitoring point 6 located in the slope reaches the saturated water content after $72 \mathrm{~h}$ of rainfall. For monitoring points $3,7,10$, and 11 , the increase rate of volumetric moisture content decreases from top to bottom in the vertical 
TABLE 2: Calculation parameters of road bed and pavement materials.

\begin{tabular}{lccccc}
\hline Material parameters & Thickness $(\mathrm{m})$ & Volume weight $\left(\mathrm{kN} / \mathrm{m}^{3}\right)$ & Elastic modulus $(\mathrm{MPa})$ & Poisson's ratio & Damping ratio (\%) \\
\hline Pavement surface & 0.15 & 25.0 & 1200.0 & 0.25 & 0.12 \\
Pavement base & 0.36 & 24.0 & 1100.0 & 0.27 & 0.10 \\
Embankment 1 & 8.00 & 22.4 & 300.0 & 0.28 & 0.28 \\
Embankment 2 & 8.00 & 22.2 & 401.5 & 0.28 & 0.15 \\
Embankment 3 & 8.00 & 22.1 & 340.0 & 0.33 & 0.15 \\
Subgrade & 15.00 & 19.0 & 200.0 & & 0.22 \\
\hline
\end{tabular}

TABle 3: Physical and mechanical parameters.

\begin{tabular}{|c|c|c|c|c|c|c|c|c|}
\hline & $\begin{array}{l}\text { Optimum } \\
\text { moisture } \\
\text { content (\%) }\end{array}$ & $\begin{array}{l}\text { Maximum dry } \\
\text { density }\left(\mathrm{g} / \mathrm{cm}^{3}\right)\end{array}$ & $\begin{array}{c}\text { Saturated } \\
\text { water content } \\
(\%)\end{array}$ & $\begin{array}{l}\text { Cohesion } \\
(\mathrm{kPa})\end{array}$ & $\begin{array}{l}\text { Internal } \\
\text { friction } \\
\text { angle }\left(^{\circ}\right)\end{array}$ & $\begin{array}{c}\text { Elastic } \\
\text { modulus } \\
(\mathrm{MPa})\end{array}$ & $\begin{array}{c}\text { Saturated } \\
\text { permeability } \\
\text { coefficient }(\mathrm{m} / \mathrm{s})\end{array}$ & $\begin{array}{c}\text { Unit } \\
\text { weight } \\
\left(\mathrm{kN} / \mathrm{m}^{3}\right)\end{array}$ \\
\hline $\begin{array}{l}\text { Gradation } \\
1\end{array}$ & 6.6 & 2.24 & 38.33 & 30.0 & 21.9 & 300.0 & $5.88 \times 10^{-7}$ & 22.4 \\
\hline $\begin{array}{l}\text { Gradation } \\
2\end{array}$ & 6.0 & 2.22 & 36.56 & 37.6 & 20.2 & 401.5 & $3.45 \times 10^{-7}$ & 22.2 \\
\hline $\begin{array}{l}\text { Gradation } \\
3\end{array}$ & 6.0 & 2.21 & 37.44 & 30.8 & 20.5 & 340.0 & $4.09 \times 10^{-7}$ & 22.1 \\
\hline
\end{tabular}

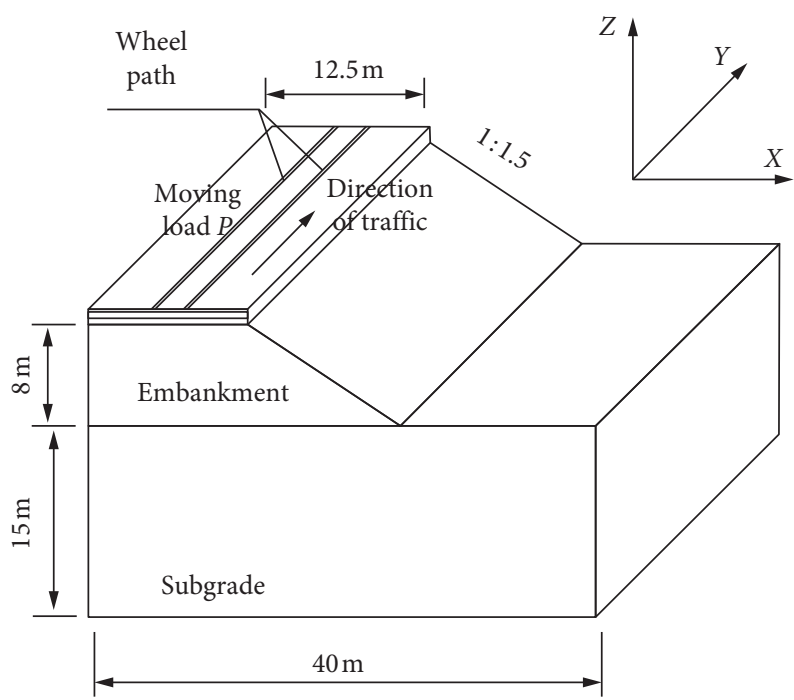

Figure 2: Moving dead load model.

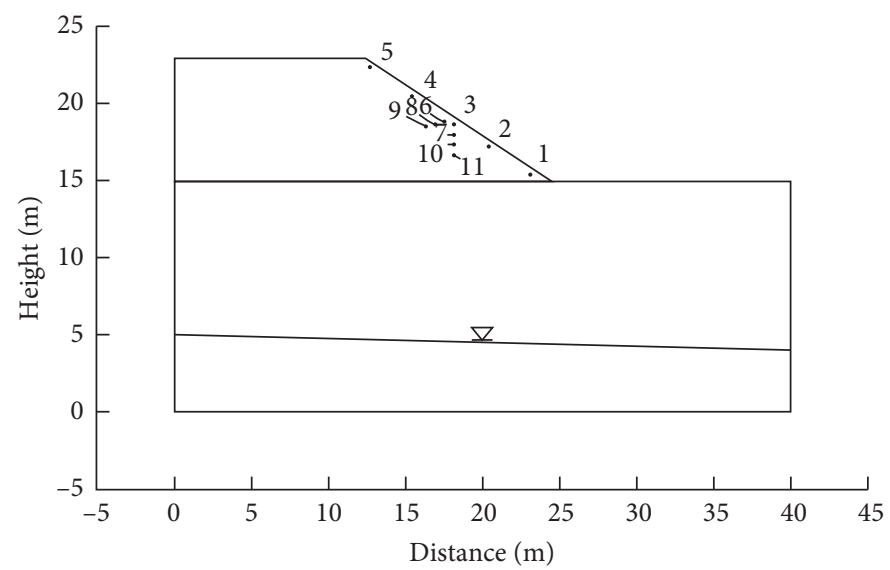

- Monitoring point

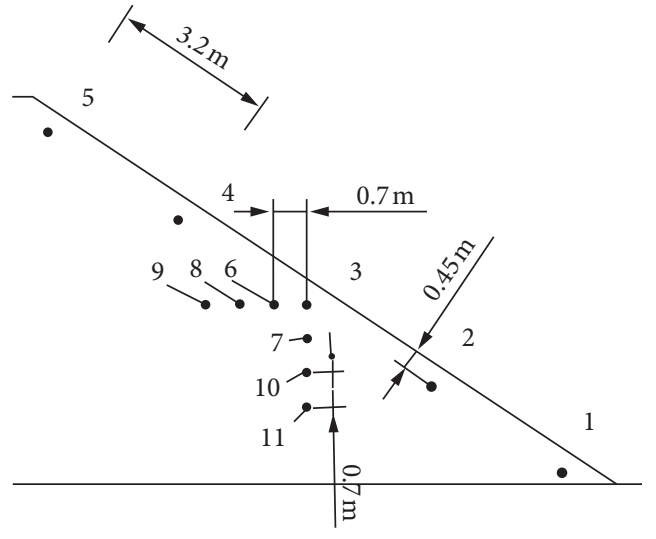

(b)

FIgURE 3: Numerical analysis model of embankment seepage. (a) Overall model diagram. (b) Specific location of monitoring points. 

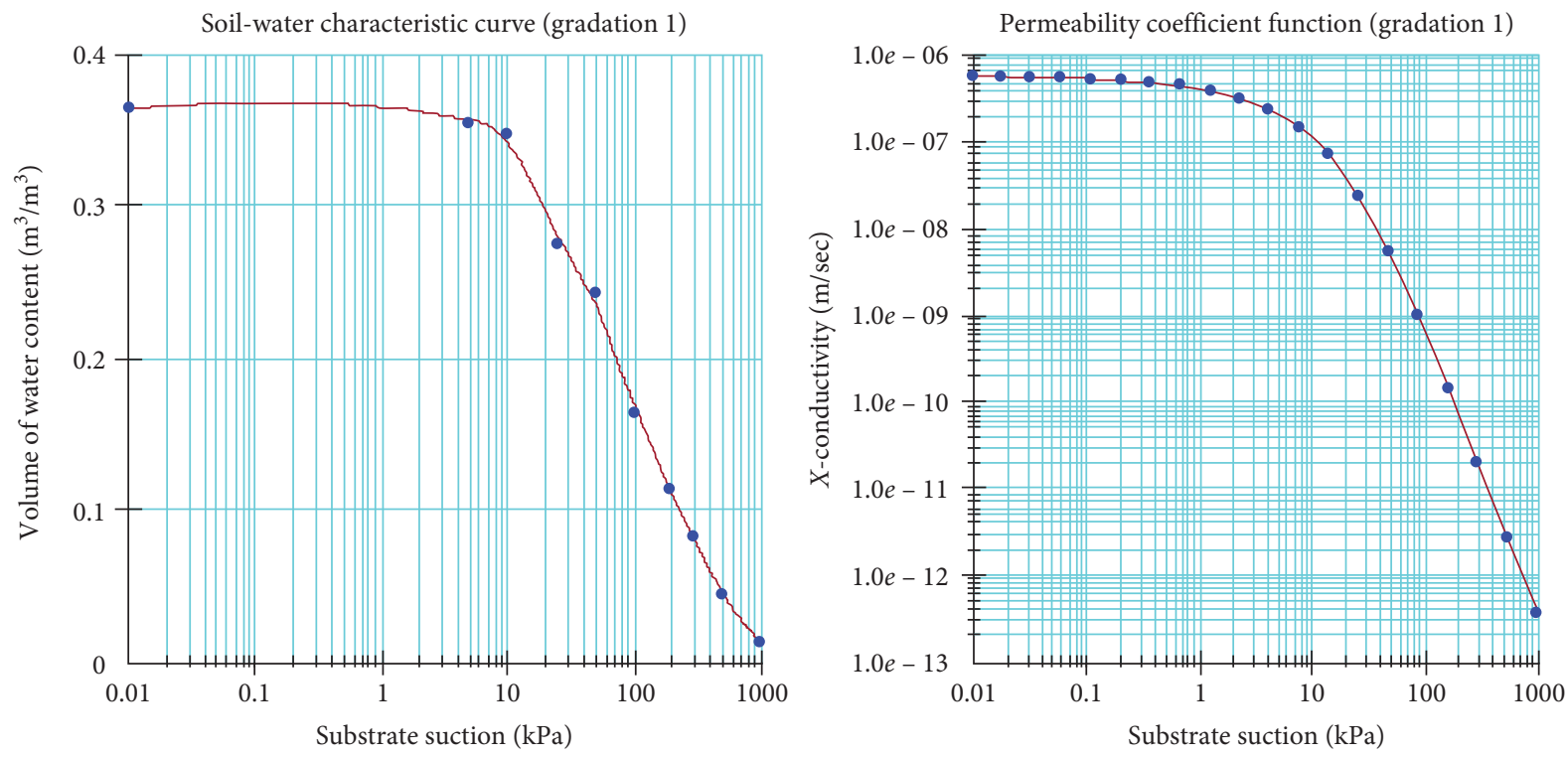

(a)
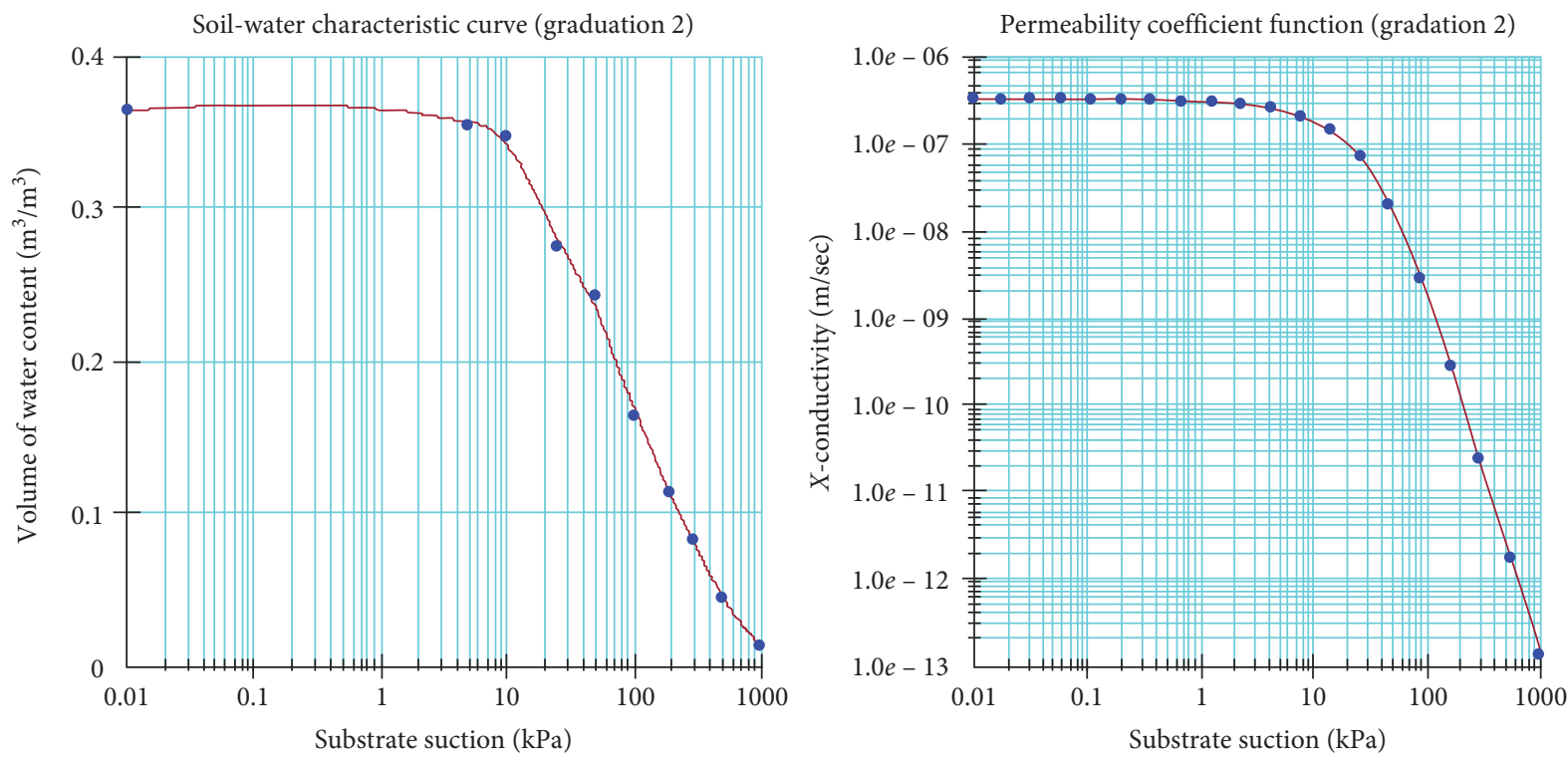

(b) 

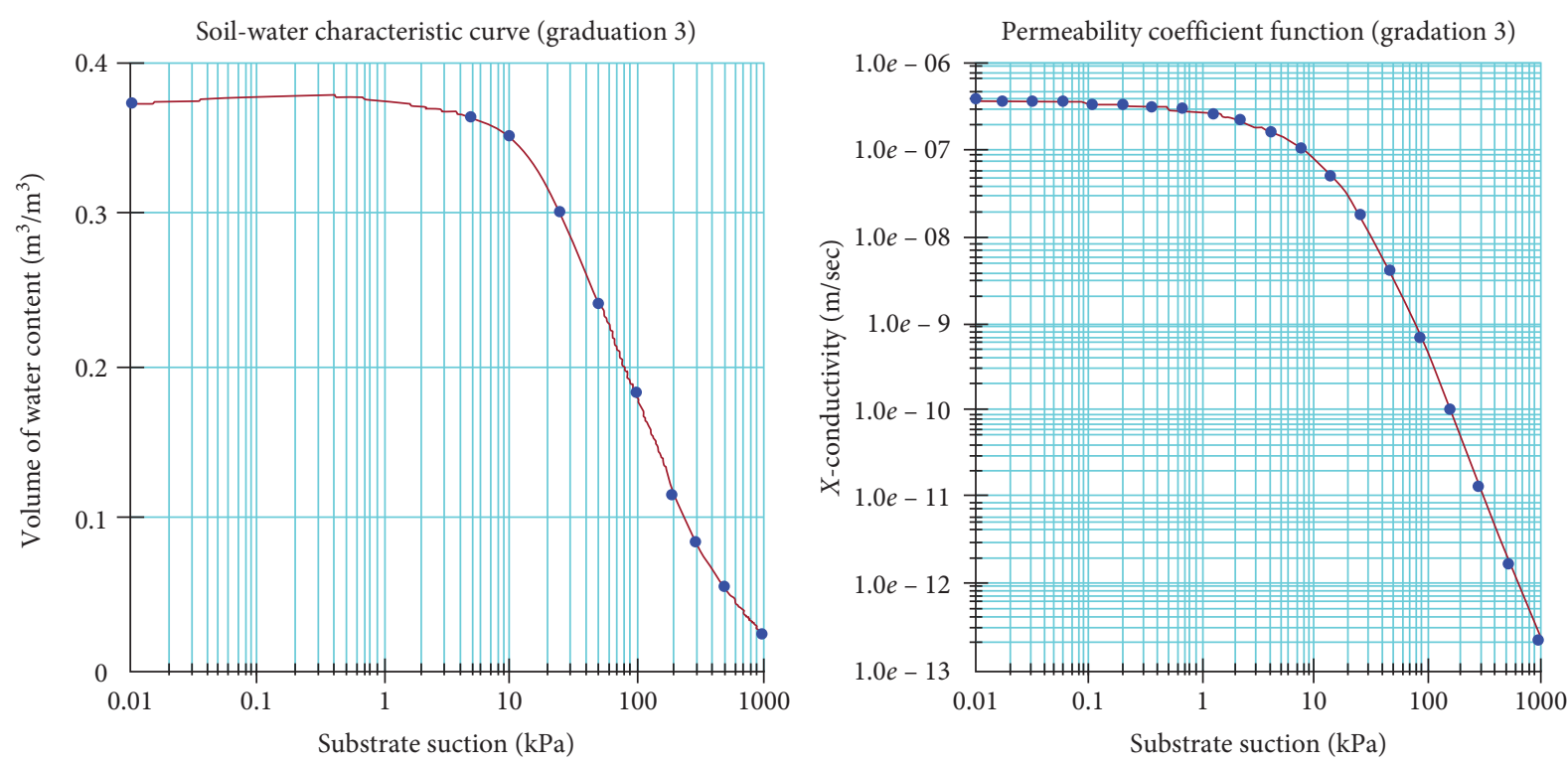

(c)

FIGURE 4: Fitting soil-water characteristic curve and permeability coefficient curve of carbonaceous mudstone coarse-grained soil. (a) Gradation 1. (b) Gradation 2. (c) Gradation 3.

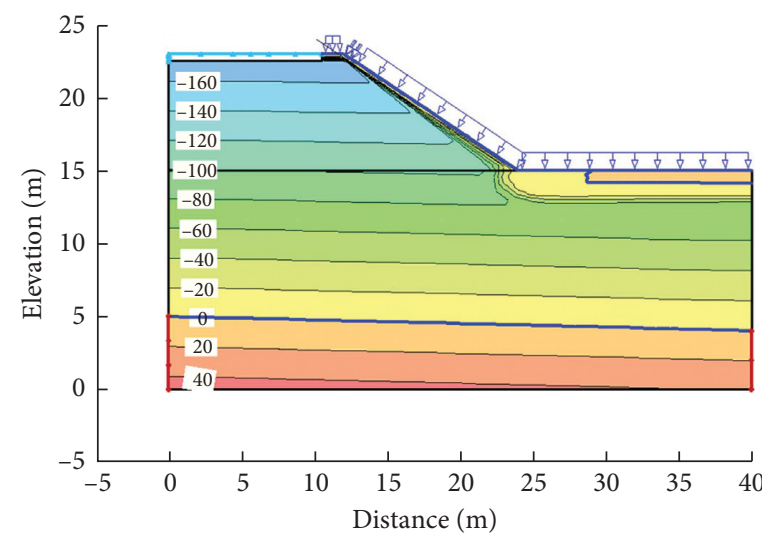

(a)

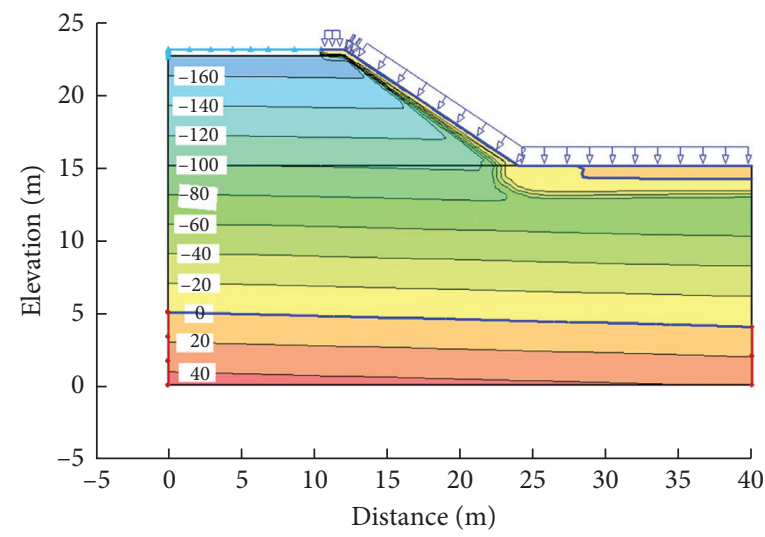

(c)

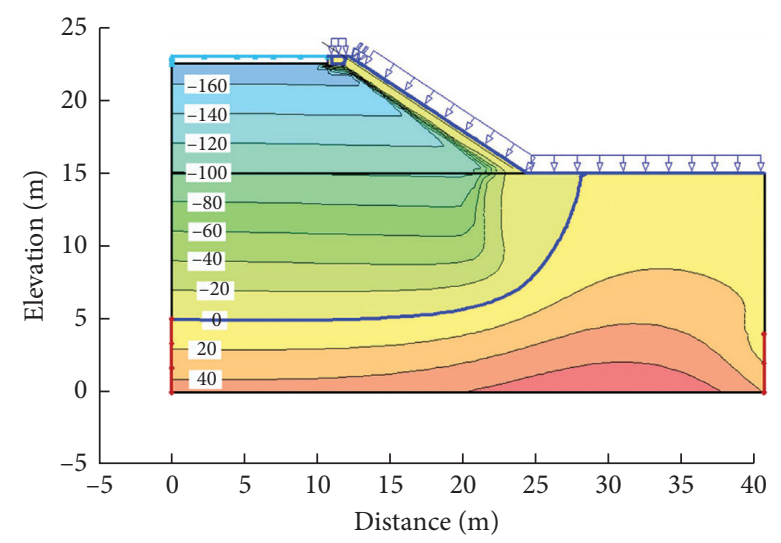

(b)

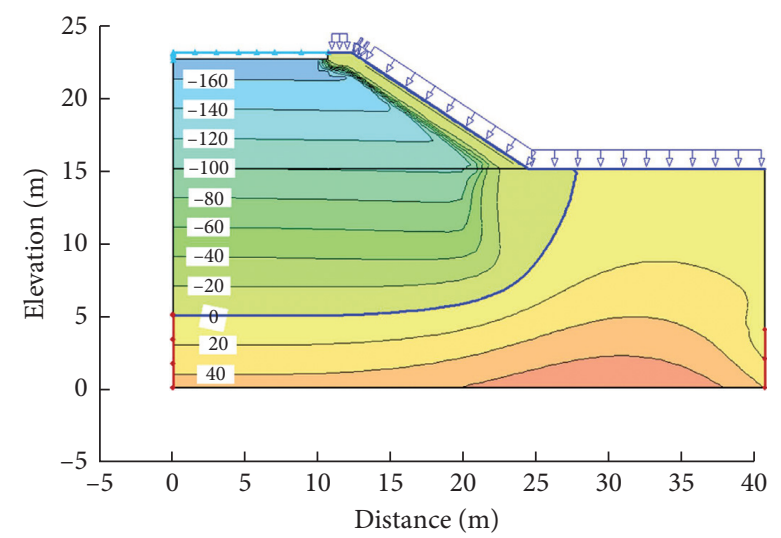

(d) 


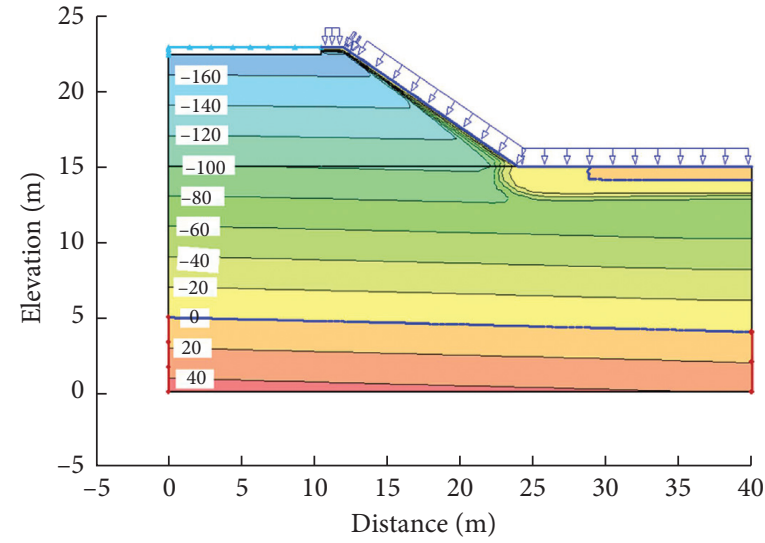

(e)

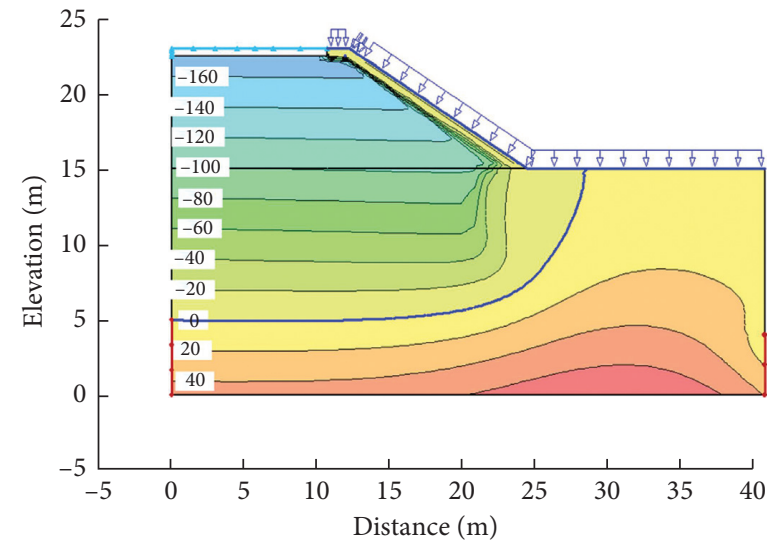

(f)

FiguRE 5: Cloud chart of the pore water pressure of carbonaceous mudstone coarse-grained soil embankment. (a) Gradation 1 (24h rainfall). (b) Gradation 1 ( $72 \mathrm{~h}$ rainfall). (c) Gradation 2 ( $24 \mathrm{~h}$ rainfall). (d) Gradation 2 ( $72 \mathrm{~h}$ rainfall). (e) Gradation 3 (24h rainfall). (f) Gradation 3 (72 h rainfall).

direction of embankment slope. For monitoring points $3,6,8$, and 9 , the volumetric moisture content decreases from the slope surface to the slope interior in the horizontal direction of the embankment slope. Specifically, the wetting front expands from the slope surface to the slope interior.

In conclusion, the negative pore water pressure of soil embankment decreases under the effect of rainfall, and the water volume content of the area affected by rainfall infiltration increases or reaches the saturated water content. The changes in the above physical quantities can be summarized in the following two points: (1) the water content of carbonaceous mudstone coarse-grained soil increases, and the surface tension of soil decreases gradually after rainwater infiltration in the embankment. This condition results in the rapid decrease in the negative pore water pressure of soil until it reaches $0 \mathrm{kPa}$. However, the monitoring points located in the embankment far from the slope surface are less affected by rainwater infiltration. Thus, the change in pore water pressure is unremarkable. (2) The influence degree of rock and soil slopes affected by rainfall is related to the rainfall time. The longer the rainfall time, the greater the rainfall infiltration depth. Under the action of gravity and head difference, the rainwater infiltrating in the slope moves to the lower and front of the carbonaceous mudstone coarse-grained soil embankment. With the increase in rainfall duration, the range and depth of transient saturation zone expand along the slope direction.

2.3. Variation Law of the Seepage Velocity Vector. The rainwater migrates inside and forms a seepage field after it infiltrates into the surface of the carbonaceous mudstone coarse-grained soil embankment. During seepage, the rainwater fills the pores of the coarse-grained soil particles and exerts a drag force on the coarse-grained soil particles, forming a seepage force. The size and direction of this force can be expressed with the seepage velocity vector generated by the embankment. The seepage velocity vector calculation results of different soil samples are shown in Figure 7.
As shown in Figure 8, the variation trend of the seepage velocity vector of three soil samples is similar. The smaller the saturated permeability coefficient and saturated water content of embankment, the larger the seepage velocity vector. Under the action of atmospheric rainfall, the seepage field first forms on the surface of carbonaceous mudstone coarse-grained soil embankment slope. When the rainfall is $24 \mathrm{~h}$, the seepage velocity vector is mainly concentrated below the soil shoulder, and the arrow length is large, forming a dense area of seepage velocity vector. When the rainfall reaches $72 \mathrm{~h}$, the seepage velocity vector at the toe of the embankment slope gradually turns upward at the groundwater level, forming a return flow zone. This phenomenon may be due to the following reasons. In the initial stage of rainfall, part of the rainwater collects and infiltrates at the soil shoulder of the embankment because it is relatively flat. This condition results in a large amount of rainwater infiltration under the soil shoulder and a rapid seepage speed, forming a dense seepage area. With the continuous rainfall, the rainwater infiltrating in the slope gradually collects at the foot of the slope. When the rainwater expands to the groundwater level, the groundwater level gradually climbs up along the foot of the slope, forming a return flow zone.

\section{Analysis of the Stress and Deformation Characteristics of Embankment}

3.1. Dynamic Simulation Scheme. The data of embankment pore water pressure under different rainfall conditions are imported into FLAC 3D software to investigate the influence of dynamic humidification on embankment deformation. The seepage results are combined with a dynamic model. A strength reduction method is used to calculate the stability of embankment slope with different grades of carbonaceous mudstone coarse-grained soil under dynamic humidification.

The moving dead load model adopted in this study is shown in Figure 3. The vehicle load before the dynamic loading of the carbonaceous mudstone coarse-grained soil embankment model is based on the calculation method of 


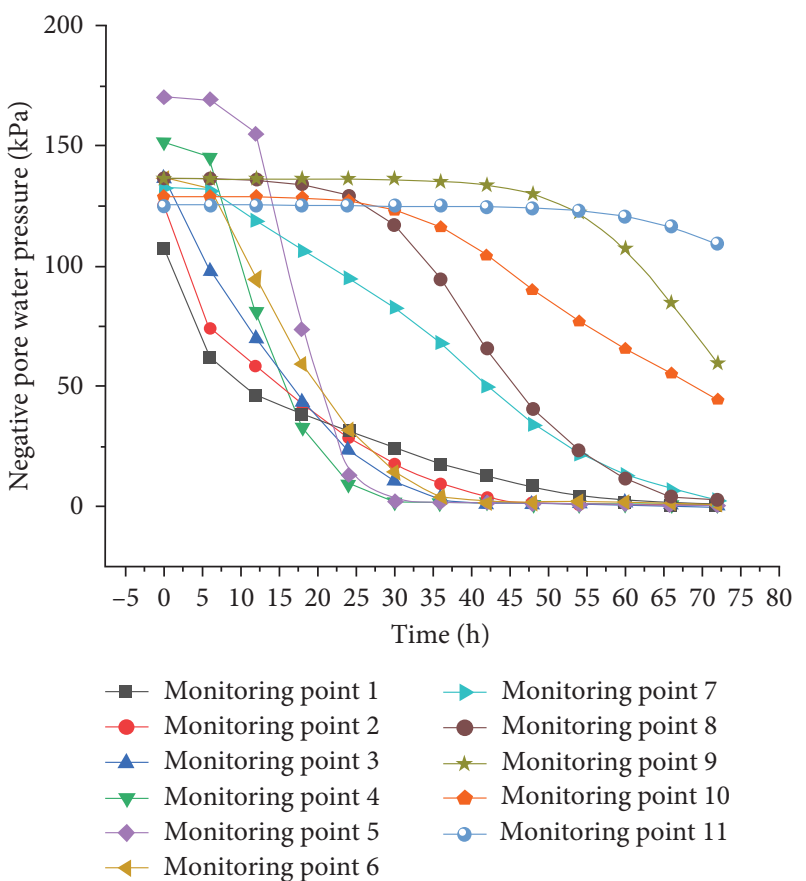

(a)

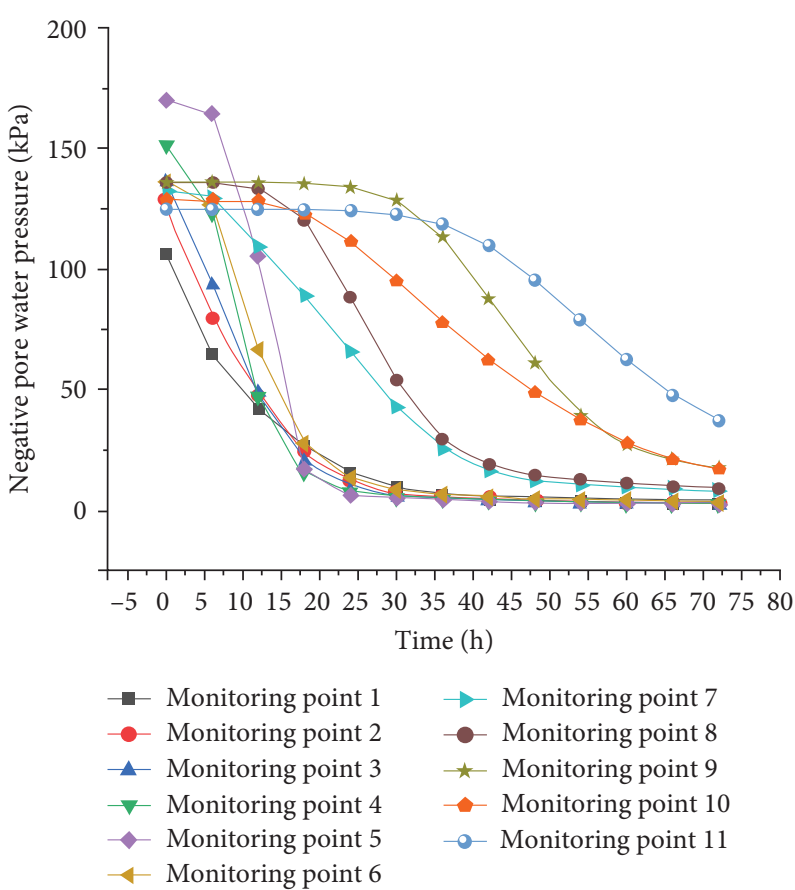

(b)

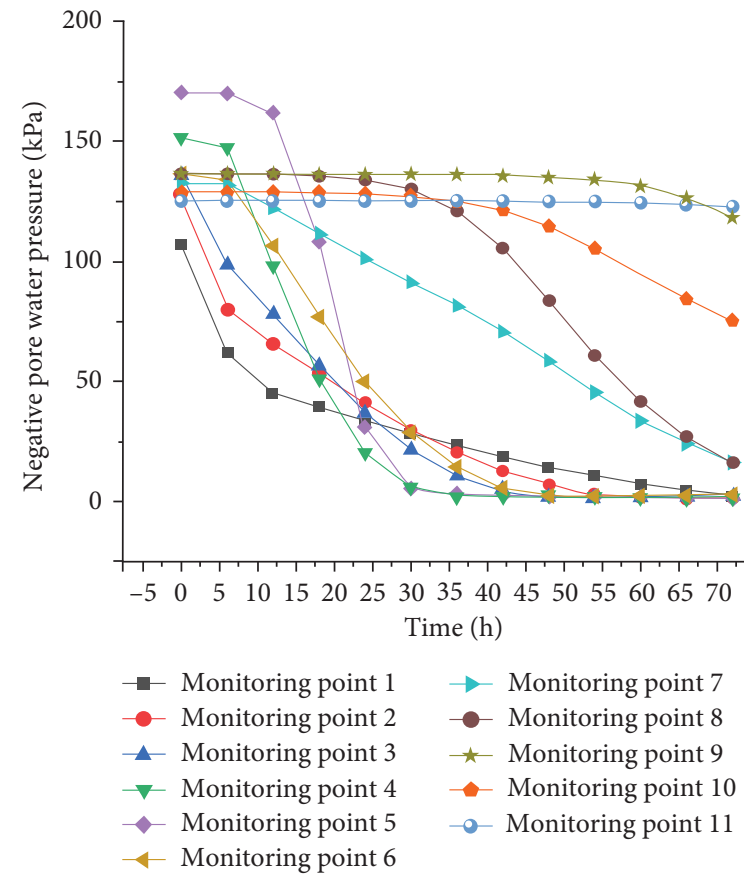

(c)

FIGURE 6: Pore water pressure variation of the monitoring points of carbonaceous mudstone coarse-grained soil embankment. (a) Gradation 1. (b) Gradation 2. (c) Gradation 3.

unit load. The equivalent circular load is simplified to $0.37 \mathrm{~m} \times 0.25 \mathrm{~m}$ rectangular load, and the vehicle load is converted into uniformly distributed load [27, 28]. The load track is set along the vehicle driving direction, and the track width and uniform load are calculated. At this time, the vehicle load is equivalent to the uniformly distributed load acting on the road, and the load size remains unchanged. The action position gradually moves along the driving direction with the movement time, and the vehicle speed can be realized by controlling the action time of the vehicle load at a certain point. The load running from the starting point to the end point of the track is regarded as one loading. This loading is imported into the seepage model of carbonaceous mudstone coarse-grained soil embankment after 24 and $72 \mathrm{~h}$ of rainfall. The model is loaded 7000 times under the standard axle load of $100 \mathrm{kN}$. 


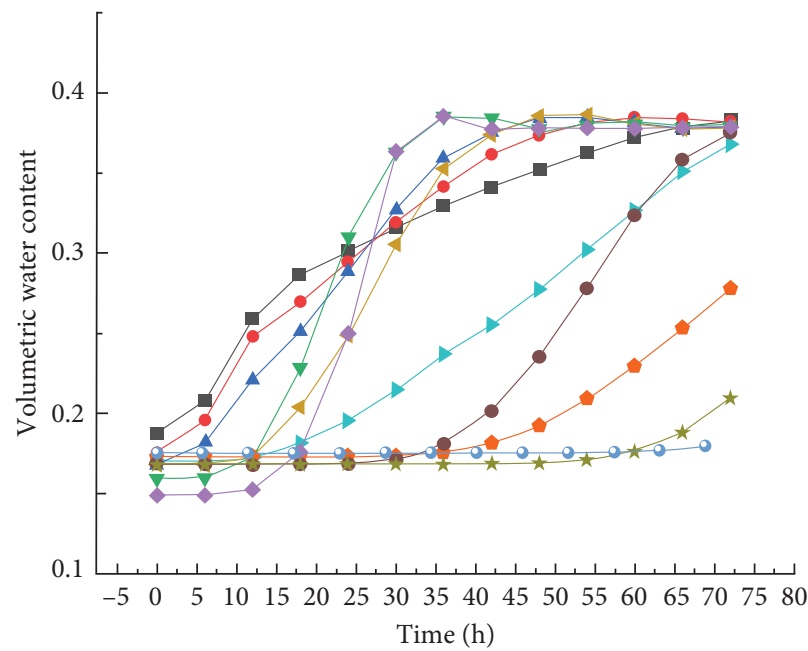

$\begin{array}{ll}- \text { Monitoring point } 1 & \rightarrow \text { Monitoring point } 7 \\ - \text { Monitoring point 2 } & - \text { Monitoring point } 8 \\ - \text { Monitoring point } 3 & \star \text { Monitoring point } 9 \\ - \text { Monitoring point } 4 & - \text { Monitoring point } 10 \\ - \text { Monitoring point } 5 & - \text { Monitoring point } 11\end{array}$

$\leftarrow$ Monitoring point 6

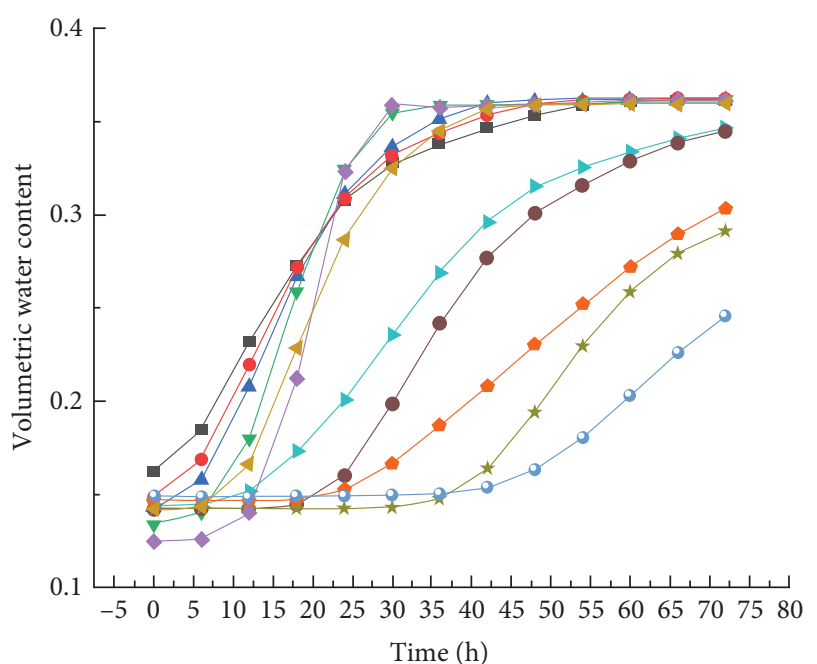

$\rightarrow$ Monitoring point $1 \rightarrow$ Monitoring point 7

- Monitoring point $2 \longrightarrow$ Monitoring point 8

- Monitoring point $3 \quad \star$ Monitoring point 9

$\checkmark$ Monitoring point $4 \_$Monitoring point 10

$\checkmark$ Monitoring point $5 \quad-$ - Monitoring point 11

- Monitoring point 6

(a)

(b)

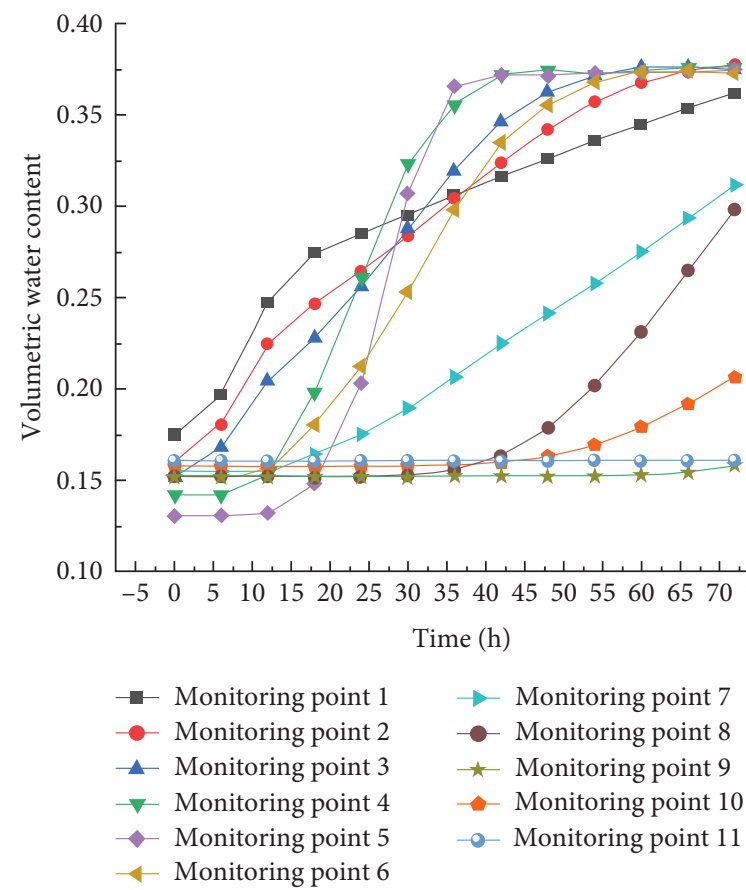

(c)

FIGURE 7: Water volume content of the monitoring points of carbonaceous mudstone coarse-grained soil embankment.

Selection of calculation parameters: the calculation parameters of road bed and pavement materials in accordance with the indoor experimental results and design data are shown in Table 2.

As shown in Table 2, the rigidity of the surface and basic structure is large. An elastic model is adopted for surface and base courses to ensure the accuracy of numerical simulation. The Mohr-Coulomb constitutive model is adopted for embankment and soil foundation. The material dissimilation of surface and basic structure is disregarded in the model calculation.

The 3D equivalent model of FLAC3D established in this study is shown in Figure 9. The shape, quantity, and size of the embankment cross section mesh are consistent with the seepage model. In the setting of boundary conditions, $Y$ constraints are applied along the boundary of vehicle driving 


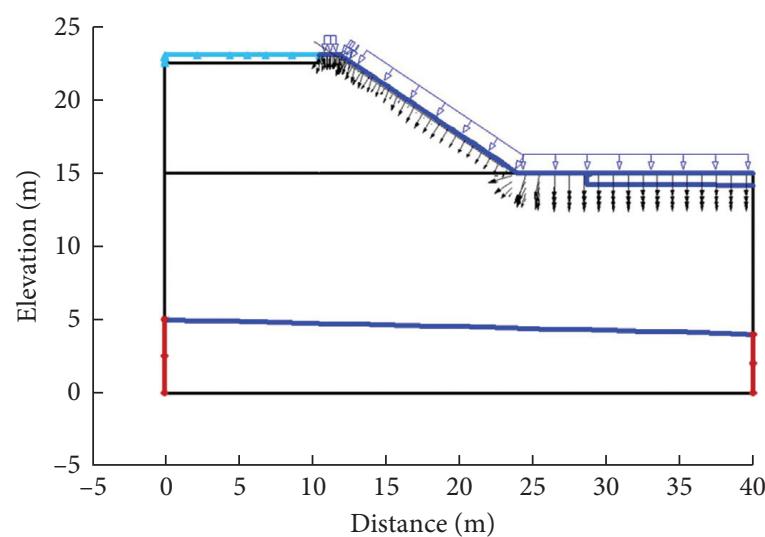

(a)

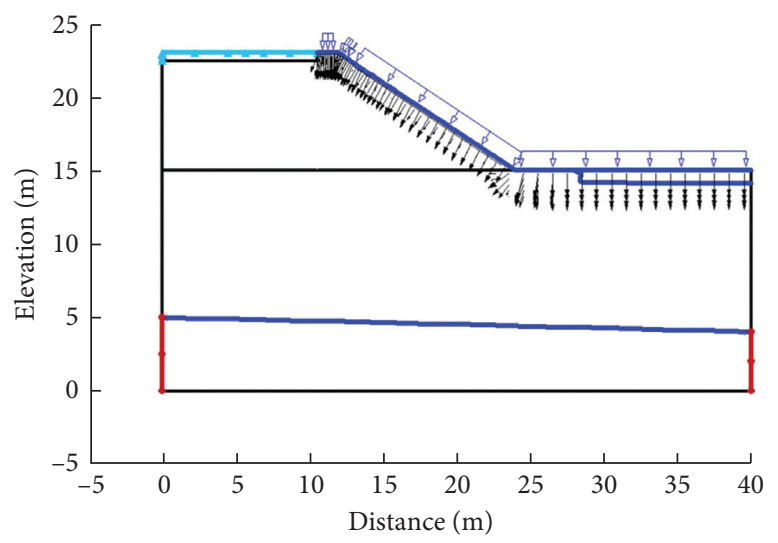

(c)

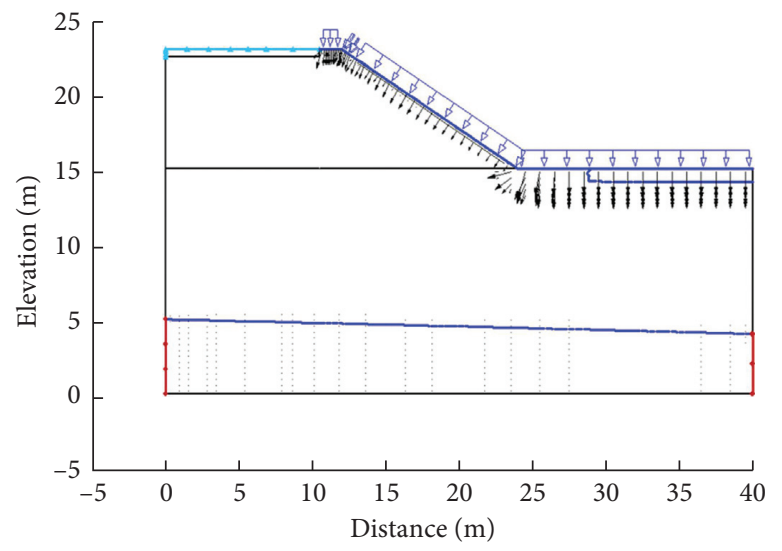

(e)

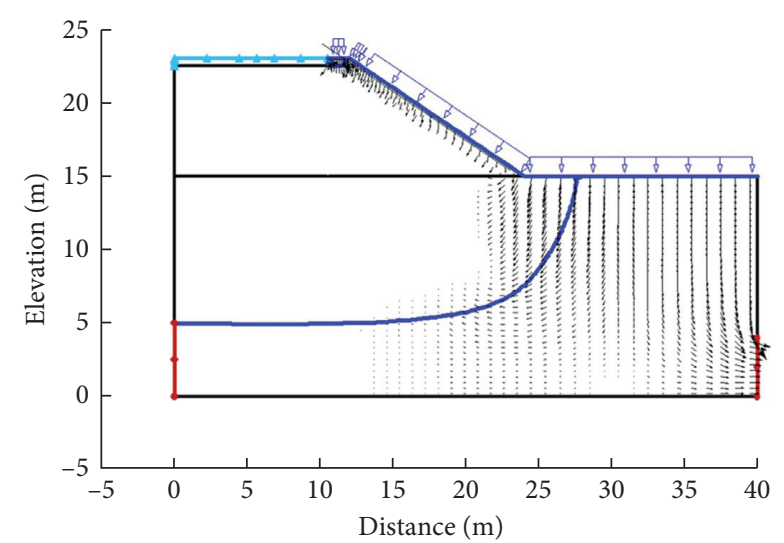

(b)

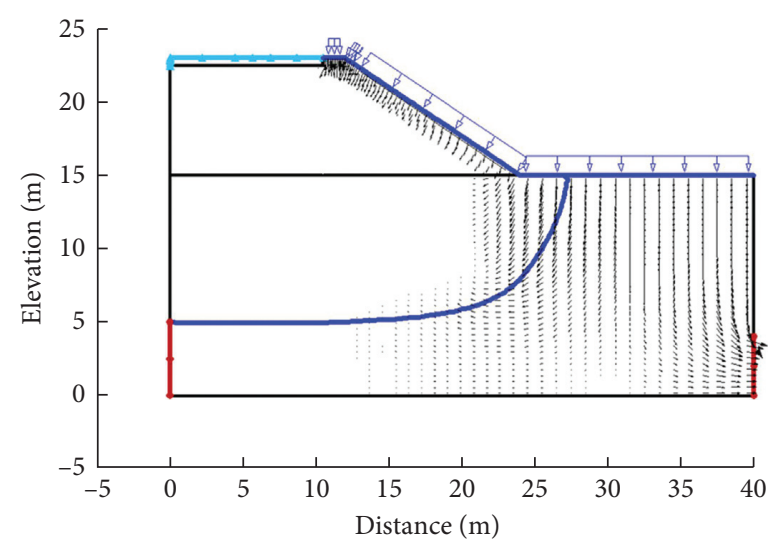

(d)

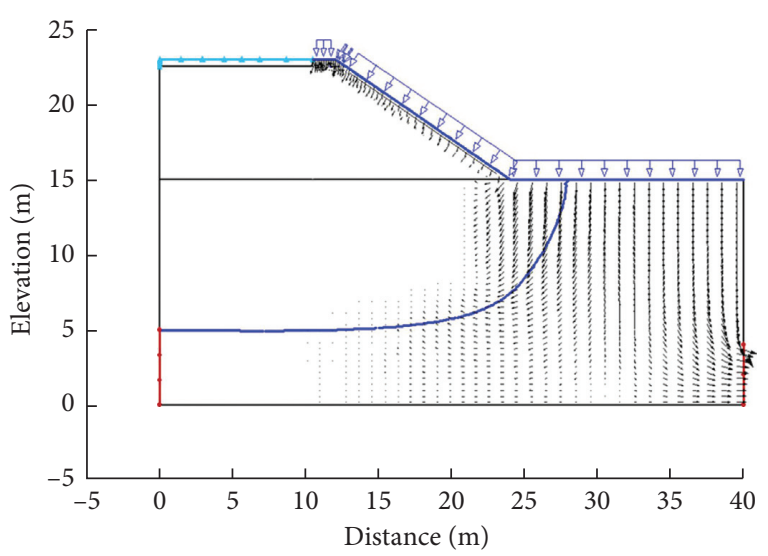

(f)

FIGURE 8: Variation law of velocity vector. (a) Gradation 1 (24h rainfall). (b) Gradation 1 ( $72 \mathrm{~h}$ rainfall). (c) Gradation 2 (24h rainfall). (d) Gradation 2 ( $72 \mathrm{~h}$ rainfall). (e) Gradation 3 ( $24 \mathrm{~h}$ rainfall). (f) Gradation 3 ( $72 \mathrm{~h}$ rainfall).

direction to ensure the accuracy of the model calculation results. $X$ and $Y$ constraints are applied perpendicular to the boundary of vehicle driving direction, and $X, Y$, and $Z$ constraints are applied at the bottom of the model. The model is loaded under the condition of $100 \mathrm{kN}$ standard axle load and $80 \mathrm{~km} / \mathrm{h}$ vehicle speed.

In this study, the vehicle load is equivalent to the uniformly distributed load on the road, which has a wide range of influence on the dynamic response of the subgrade and pavement. Selecting typical monitoring points is necessary to monitor the dynamic stress change law under the action of vehicle load. This process is performed to study the dynamic response characteristics of the subgrade within the lateral effective range. Therefore, 13 monitoring points are set on the top of the subgrade to explore the dynamic response of the same depth. On the basis on these monitoring points, the dynamic stress at different depths is analyzed. The layout of monitoring points is shown in Figure 10.

In this calculation, three types of graded carbonaceous mudstone coarse-grained soil are selected, the depth of 


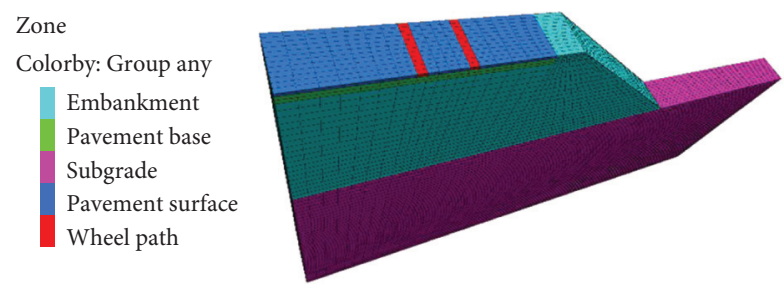

FIgURE 9: Pavement structure of numerical analysis.

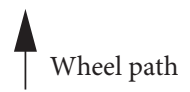

Monitoring point

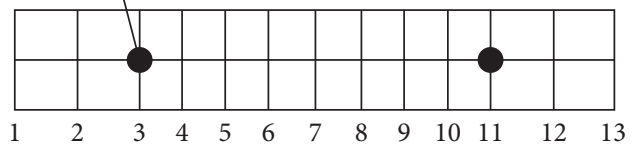

FIGURE 10: Layout of transverse monitoring points on subgrade.

subgrade working area is $1.77 \mathrm{~m}$, and unfavorable conditions are considered. Monitoring point 3 is taken as the research object, starting from the subgrade surface, every $0 \mathrm{~m}$ to study the dynamic response of carbonaceous mudstone coarsegrained soil subgrade in the vertical direction. The peak value of vertical dynamic stress at different subgrade depths is calculated at $25 \mathrm{~m}$.

\subsection{Dynamic Response Characteristics of Embankment}

\subsubsection{Dynamic Response of the Lateral Monitoring Points of} Embankment. Gradation 2 is selected as the research object in this study because the dynamic stress curves of the three soil samples are the same. In accordance with the peak stress of each monitoring point in the carbonaceous mudstone coarse-grained soil embankment, the vertical stress peak curve of the monitoring point is drawn, as shown in Figure 11.

As shown in Figure 11, the three curves all take monitoring point 7 as the center, showing an axisymmetric trend. On the subgrade surface, the peak value of vertical stress of the three soil samples at monitoring points 3 and 11 directly below the wheel reaches the maximum value, and the peak value of vertical stress at monitoring point 7 in the center of two wheels is the minimum. Therefore, when the vehicle load moves to a certain point on the subgrade surface, the vertical dynamic stress response at that point is the most obvious. With the increase in the distance from the point, the degree of vertical dynamic stress response gradually decreases.

3.2.2. Dynamic Stress Response of Embankment at Different Depths. The vertical dynamic stress peak values at different subgrade depths are calculated every $0.25 \mathrm{~m}$ from the subgrade surface to study the dynamic response of carbonaceous mudstone coarse-grained soil subgrade in the vertical direction. The calculation results are shown in Figure 12.

As shown in Figure 12, when the vehicle load is $100 \mathrm{kN}$ and the vehicle speed is $80 \mathrm{~km} / \mathrm{h}$, the vertical dynamic stress of

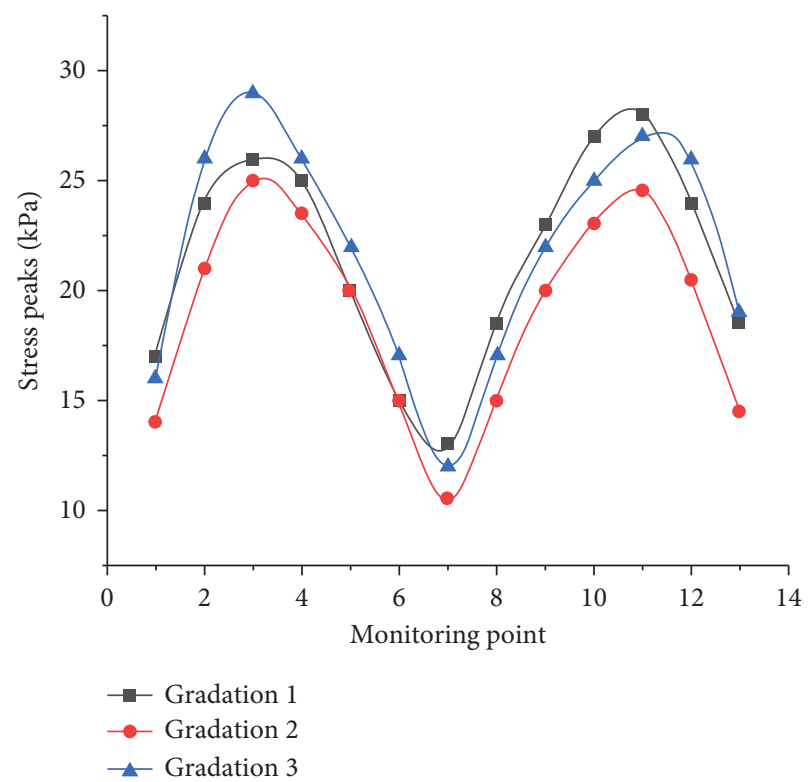

Figure 11: Peak stress curve of transverse monitoring points on subgrade surface.

three soil samples at the monitoring point gradually decreases with the increase of subgrade depth. The peak vertical dynamic stress of subgrade surface of soil sample gradation 1 is $24 \mathrm{kPa}$. When the depth of monitoring point reaches $2 \mathrm{~m}$, the peak value of vertical dynamic stress is only $3 \mathrm{kPa}$, which decreases by $87.5 \%$. The peak value of vertical dynamic stress of soil gradation 2 decreases from $25 \mathrm{kPa}$ to $4 \mathrm{kPa}$, which decreases by $84 \%$. Soil sample of gradation 3 decreased by $89.1 \%$.

3.3. Variation Law of the Embankment Settlement Displacement. Figure 13 shows the settlement displacement curve of embankment with different gradations of carbonaceous mudstone coarse-grained soil.

As shown in Figure 13, the settlement displacement of the three graded carbonaceous mudstone coarse-grained soil subgrades is extremely small, and the cumulative rate of plastic strain is low when the number of vehicle loads acting on the carbonaceous mudstone coarse-grained soil embankment with rainfall duration of 24 and $72 \mathrm{~h}$ is less than 2000 times. When the number of vehicle loads acting on the carbonaceous mudstone coarse-grained soil embankment reaches 5000 times, the settlement displacement of the three graded carbonaceous mudstone coarse-grained soil embankments increases greatly. The settlement displacement of the embankment increases to 16,14 , and $13 \mathrm{~mm}$ after $24 \mathrm{~h}$ of rainfall (plus quantity). The settlement displacement of the embankment increases to 20,19 , and $16 \mathrm{~mm}$ after $72 \mathrm{~h}$ of rainfall. The plastic deformation of carbonaceous mudstone coarse-grained soil subgrade accumulates rapidly. When the vehicle load acts on the carbonaceous mudstone coarsegrained soil embankment for 7000 times, the settlement displacement of carbonaceous mudstone coarse-grained soil subgrade with different gradations tends to be stable.

The data show that the subgrade soil is mainly elastic strain at the initial loading stage. The subgrade soil can 


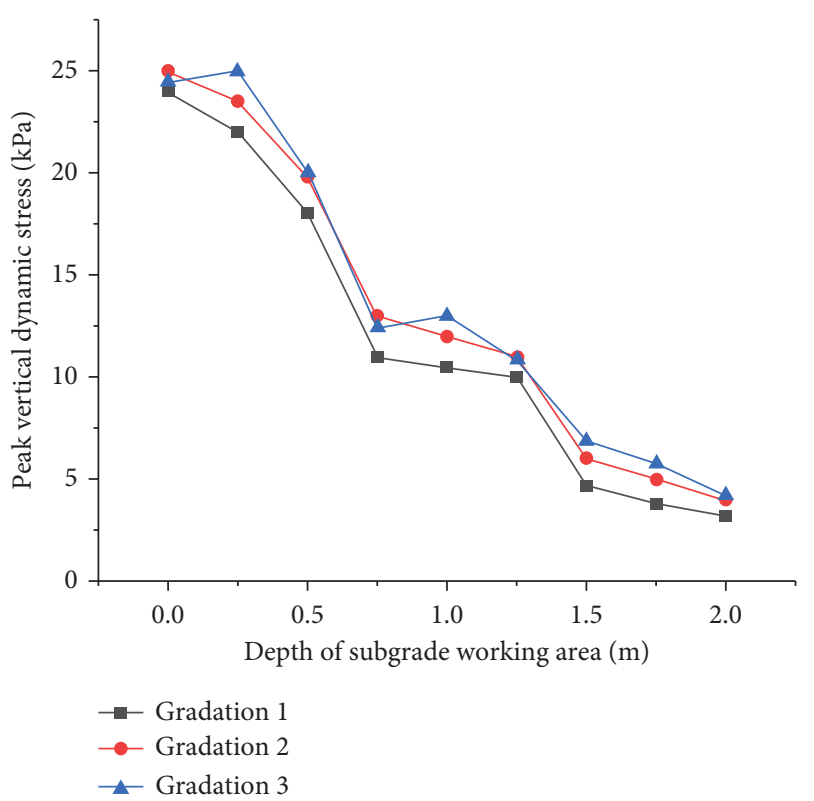

FIgURE 12: Vertical dynamic stress peak curve at different subgrade depths.

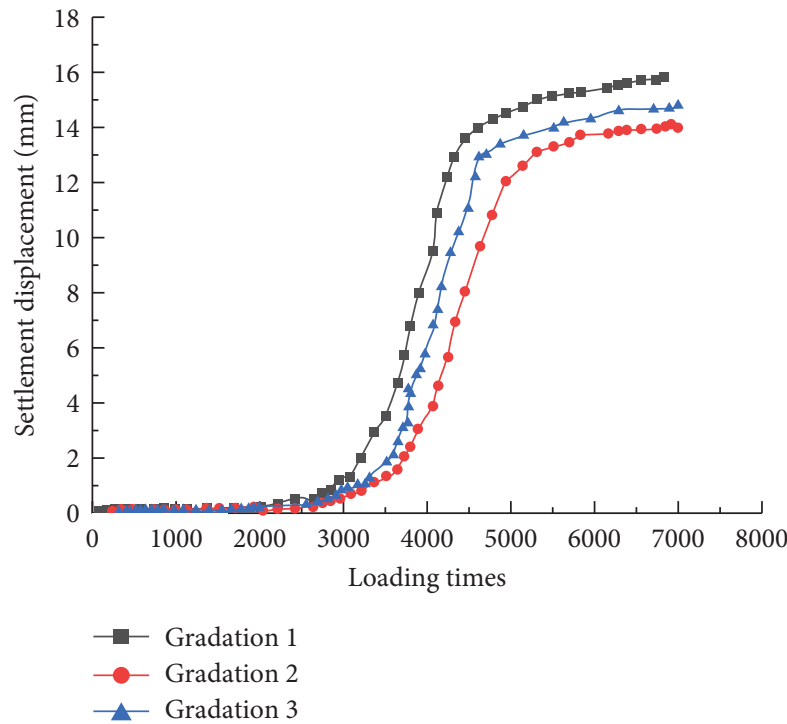

(a)

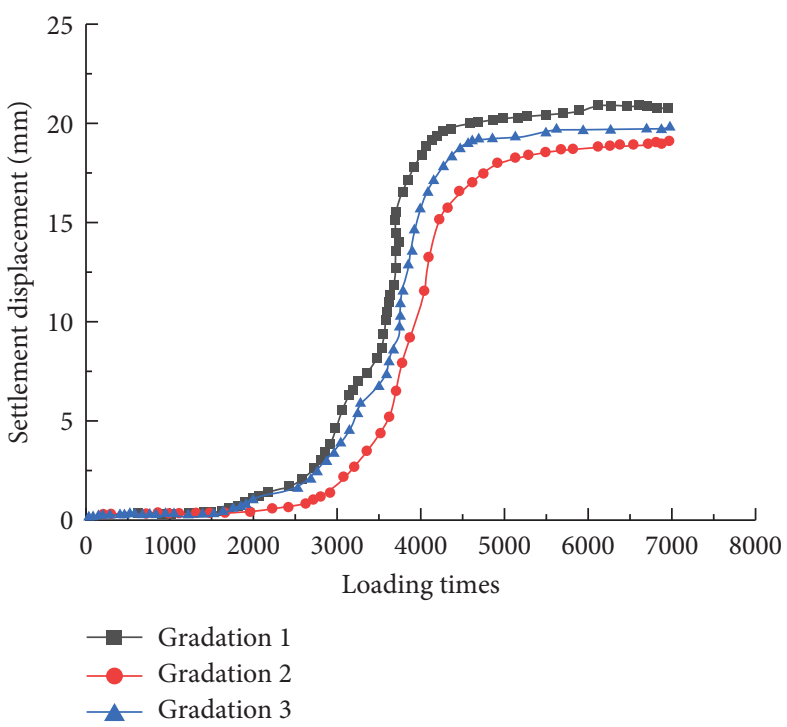

(b)

Figure 13: Displacement curve of embankment with different gradations. (a) Displacement curve of embankment (24 h). (b) Displacement curve of embankment $(72 \mathrm{~h})$.

restore to its original state in time after each loading. However, a small plastic strain still remains in the subgrade soil. With the increase in loading times, the residual plastic strain gradually accumulates, and the subgrade soil cannot restore to its original state immediately. When the loading times reach a certain degree, the subgrade soil gradually compacts, and the soil particles become close to each other. Each loading leads to the decrease in the plastic strain of the subgrade soil and gradually tends to be stable.

3.4. Variation Law of the Embankment Safety Factor. The stability of carbonaceous mudstone coarse-grained soil embankment is measured in terms of safety factor. According to the rules of the safety coefficient of The Highway Roadbed Design Specification (JTG d30-2015), the stability state of the carbonaceous mudstone coarse-grained soil embankment slope used in this study can be divided into three states: stable, unstable, and unstable, as shown in Table 4 . The variation law of the safety factor of embankment slope with different grades of carbonaceous mudstone coarse-grained soil under dynamic humidification is shown in Figure 14.

As shown in Figure 14, the safety factors of three graded carbonaceous mudstone coarse-grained soil embankments decrease with the increase in time. During $0-24 \mathrm{~h}$, the embankment safety factor of soil samples 1, 2, and 3 
TABle 4: Classification standard for the safety factor of embankment slope.

\begin{tabular}{lc}
\hline Slope condition & Safety factor standard \\
\hline Steady state & $1.35 \leq F_{S}$ \\
Unsteady state & $1.00<F_{S}<1.35$ \\
Stability failure & $F_{S} \leq 1.00$ \\
\hline
\end{tabular}

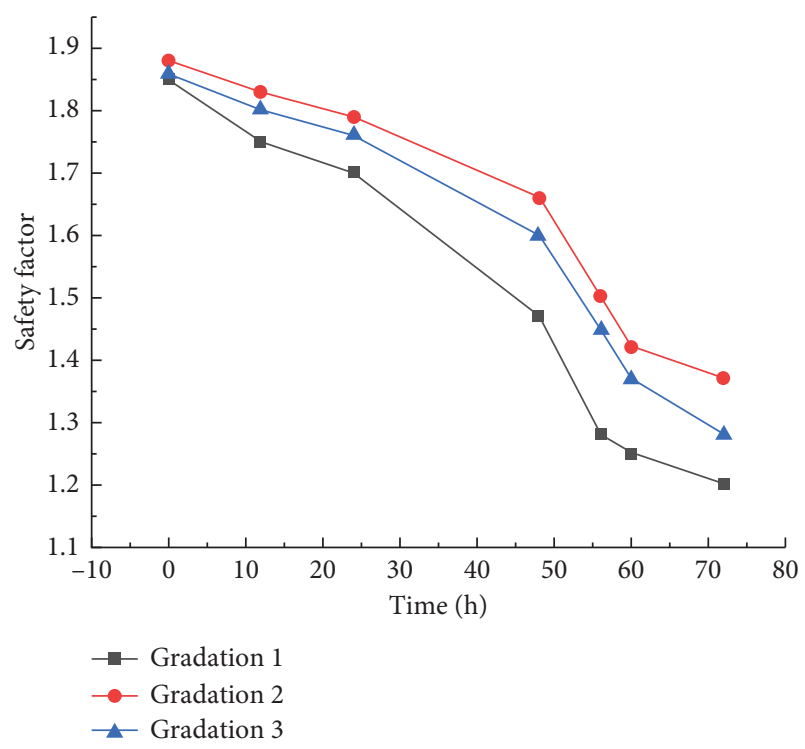

Figure 14: Variation law of safety factor.

decreases from $1.88,1.87$, and 1.85 to $1.80,1.77$, and 1.70 , respectively. The average decrease in the three soil samples is $0.003,0.004$, and 0.006 per hour, respectively. The embankment safety factor shows a small decline. When the study lasted for 24-72 h, the embankment safety factor of soil samples 1, 2, and 3 decreases to $1.38,1.28$, and 1.20, respectively. The average decrease rate of the three soil samples is 0.01 per hour, and the decrease rate of safety factor increases considerably. When the rainfall lasted for $72 \mathrm{~h}$, the safety factor reaches the lowest value. The safety factor of soil sample 2 is greater than that of other soil samples at the same time, and the safety factor of soil sample 1 is the lowest. In accordance with the above data, the variation law of embankment safety factor shows a trend of slow decrease at first and then rapid decrease during the whole study period.

Slow decreasing stage: in the initial stage of rainfall, the infiltration depth of rainwater on the surface of embankment slope is limited. The effect on the embankment slope of carbonaceous mudstone coarse-grained soil is relatively small, and the number of vehicle loads is minimal. Thus, the safety factor of the embankment slope of carbonaceous mudstone coarse-grained soil has a small downward trend. Rapid reduction stage: with the continuous influence of dynamic humidification, the seepage velocity vector of embankment slope gradually increases. The contribution of seepage force to slope stability is gradually obvious, resulting in the rapid decline rate of embankment safety factor.

\section{Conclusion}

(1) After the beginning of rainfall, the matric suction near the embankment slope decreases rapidly, the volume moisture content of soil increases rapidly. The wetting front expands from the slope surface to the slope interior, and the negative pore water pressure of gradation 2 decreases rapidly from $120 \mathrm{kPa}$ to $40 \mathrm{kPa}$ within $35-72 \mathrm{~h}$ of rainfall, which decreases by $66 \%$. Under the condition of the same rainfall time, the greater the nonuniformity coefficient, the faster the decrease in the pore water pressure of the soil sample at the same monitoring point.

(2) The smaller the saturated permeability coefficient and saturated water content are, the larger the seepage velocity vector is.

(3) At the initial loading stage, the carbonaceous mudstone coarse-grained soil subgrade mainly produces recoverable elastic strain that can be recovered after driving. However, a small irrecoverable plastic deformation is still found under the elastic deformation. This deformation gradually accumulates and develops into settlement displacement under the cyclic action of vehicle load. When the settlement displacement reaches a certain position, the gap between the soil particles decreases gradually, causing the subgrade soil to be dense, and the settlement displacement tends to be stable. In the stable stage, the larger the nonuniformity coefficient, the smaller the settlement displacement.

(4) Under the effect of dynamic humidification, the variation of embankment safety factor in the whole study period shows a trend of slow reduction at first and then rapid reduction. In the slow reduction stage, gradations 1,2 , and 3 decrease by $0.003,0.004$, and 0.006 per hour on average, respectively. In the rapid reduction stage, all the three soil samples decrease by 0.01 per hour on average. On the whole, the safety factor of the soil sample with large nonuniformity coefficient is better than that of the two other graded carbonaceous mudstone coarsegrained soil samples.

\section{Data Availability}

The data used to support the finding of this study are available from the corresponding author upon request.

\section{Conflicts of Interest}

The authors declare that there are no conflicts of interest regarding the publication of this paper.

\section{Acknowledgments}

This research was financially supported by the Open Fund of Guangxi Key Laboratory of Road Structure and Materials 
(2020gxjgclkf002) and the National Natural Science Foundation of China (Grant no. 51978084).

\section{References}

[1] T. Guo, "Evaluation of highly thermally mature shale-gas reservoirs in complex structural parts of the Sichuan basin," Journal of Earth Science, vol. 24, no. 6, pp. 863-873, 2013.

[2] L. Zeng, X. Yao, J. Zhang, Q.-F. Gao, J. Chen, and Y. Gui, "Ponded infiltration and spatial-temporal prediction of the water content of silty mudstone," Bulletin of Engineering Geology and the Environment, vol. 79, no. 10, pp. 5371-5383, 2020.

[3] Z. He, Y. Liu, H. Tang, Y. Xing, and H. Bian, "Experimental study on cumulative plastic deformation of coarse-grained soil high-grade roadbed under long-term vehicle load," $A d$ vances in Civil Engineering, vol. 2018, Article ID 8167205, 8 pages, 2018.

[4] Z. He and B. Wang, "Instability process model test for bedding rock slope with weak interlayer under different rainfall conditions," Advances in Civil Engineering, vol. 2018, Article ID 8201031, 8 pages, 2018.

[5] X. Q. Wang, W. L. Zou, Y. D. Luo, W.-D. Deng, and Z. Wang, "Influence of compaction degree and gradation on SWCC of compacted clay soil," Rock and Soil Mechanics, vol. 32, no. 4, pp. 181-184, 2011.

[6] H. Rahardjo, T. H. Ong, R. B. Rezaur, and E. C. Leong, "Factors controlling instability of homogeneous soil slopes under rainfall," Journal of Geotechnical and Geoenvironmental Engineering, vol. 133, no. 12, pp. 1532-1543, 2007.

[7] S. Cuomo and M. Della Sala, "Rainfall-induced infiltration, runoff and failure in steep unsaturated shallow soil deposits," Engineering Geology, vol. 162, pp. 118-127, 2013.

[8] Y. Wang, J. Chai, J. Cao, Y. Qin, Z. Xu, and X. Zhang, "Effects of seepage on a three-layered slope and its stability analysis under rainfall conditions," Natural Hazards, vol. 102, no. 3, pp. 1269-1278, 2020.

[9] J.-P. Wang, N. Hu, B. François, and P. Lambert, "Estimating water retention curves and strength properties of unsaturated sandy soils from basic soil gradation parameters," Water Resources Research, vol. 53, no. 7, pp. 6069-6088, 2017.

[10] M. Feng, J. Wu, D. Ma, X. Ni, B. Yu, and Z. Chen, "Experimental investigation on the seepage property of saturated broken red sandstone of continuous gradation," Bulletin of Engineering Geology and the Environment, vol. 77, no. 3, pp. 1167-1178, 2018.

[11] C. F. Chiu, W. M. Yan, and K.-V. Yuen, "Estimation of water retention curve of granular soils from particle-size distribution-a Bayesian probabilistic approach," Canadian Geotechnical Journal, vol. 49, no. 9, pp. 1024-1035, 2012.

[12] F. Meng, J.-s. Zhang, X.-b. Chen, and Q.-y. Wang, "Deformation characteristics of coarse-grained soil with various gradations," Journal of Central South University, vol. 21, no. 6, pp. 2469-2476, 2014.

[13] K. Liu, P. J. Vardon, M. A. Hicks, and P. Arnold, "Combined effect of hysteresis and heterogeneity on the stability of an embankment under transient seepage," Engineering Geology, vol. 219, pp. 140-150, 2017.

[14] M. S. Kim, Y. Onda, T. Uchida, J. K. Kim, and Y. S. Song, "Effect of seepage on shallow landslides in consideration of changes in topography: case study including an experimental sandy slope with artificial rainfall," Catena, vol. 161, pp. 5062, 2018.
[15] J. Kim, W. Hwang, and Y. Kim, "Effects of hysteresis on hydro-mechanical behavior of unsaturated soil," Engineering Geology, vol. 245, pp. 1-9, 2018.

[16] L. Z. Wu, Y. Zhou, P. Sun, J. S. Shi, G. G. Liu, and L. Y. Bai, "Laboratory characterization of rainfall-induced loess slope failure," Catena, vol. 150, pp. 1-8, 2017.

[17] J. Liu, C. Yang, J. Gan, Y. Liu, L. Wei, and Q. Xie, "Stability analysis of road embankment slope subjected to rainfall considering runoff-unsaturated seepage and unsaturated fluid-solid coupling," International Journal of Civil Engineering, vol. 15, no. 6A, pp. 865-876, 2017.

[18] C. Volz, P.-J. Frank, D. F. Vetsch, W. H. Hager, and R. M. Boes, "Numerical embankment breach modelling including seepage flow effects," Journal of Hydraulic Research, vol. 55, no. 4, pp. 480-490, 2017.

[19] J. Kim, S. Jeong, and R. A. Regueiro, "Instability of partially saturated soil slopes due to alteration of rainfall pattern," Engineering Geology, vol. 147-148, pp. 28-36, 2012.

[20] S. E. Cho, "Probabilistic stability analysis of rainfall-induced landslides considering spatial variability of permeability," Engineering Geology, vol. 171, pp. 11-20, 2014.

[21] T. S. Nguyen and S. Likitlersuang, "Reliability analysis of unsaturated soil slope stability under infiltration considering hydraulic and shear strength parameters," Bulletin of Engineering Geology and the Environment, vol. 78, no. 8, pp. 5727-5743, 2019.

[22] H. Fu, J. Liu, and H. Zha, "Study of the strength of disintegrated carbonaceous mudstone modified with nano$\mathrm{Al}_{2} \mathrm{O}_{3}$ and cement," Journal of Nanoscience and Nanotechnology, vol. 20, no. 8, pp. 4839-4845, 2020.

[23] Z.-M. He, D. Xiang, Y.-X. Liu, Q.-F. Gao, and H.-B. Bian, "Deformation behavior of coarse-grained soil as an embankment filler under cyclic loading," Advances in Civil Engineering, vol. 2020, Article ID 4629105, 13 pages, 2020.

[24] M. Kai, Research on hydraulic characteristics of carbon mudstone and postonstruction dynamic deformation properties of embankment, Master's dissertation, vol. 2013, Changsha University of Science and Technology, Changsha, China, 2013.

[25] Z. A. Erguler and R. Ulusay, "Assessment of physical disintegration characteristics of clay-bearing rocks: disintegration index test and a new durability classification chart," Engineering Geology, vol. 105, no. 1-2, pp. 11-19, 2009.

[26] J. Zhang, F. Li, L. Zeng, J. Peng, and J. Li, "Numerical simulation of the moisture migration of unsaturated clay embankments in southern China considering stress state," Bulletin of Engineering Geology and the Environment, vol. 80, no. 1, pp. 11-24, 2021.

[27] R. Blab and J. T. Harvey, "Modeling measured 3D tire contact stresses in a viscoelastic FE pavement model," International Journal of Geomechanics, vol. 2, no. 3, pp. 271-290, 2002.

[28] L. Sun and T. W. Kennedy, "Spectral analysis and parametric study of stochastic pavement loads," Journal of Engineering Mechanics, vol. 128, no. 3, pp. 318-327, 2002. 